\title{
A Study on Professional Technology Business Incubator and Its Operation Mode
}

\author{
Yong Wang \\ School of Economics and Management, \\ Southeast University, \\ Nanjing, China \\ Zhejiang Business College, \\ Hangzhou, China \\ E-mai: 1318226182@qq.com
}

\author{
Jie Xu \\ Zhejiang Business College, \\ Hangzhou, China \\ E-mail:65166756@qq.com
}

\begin{abstract}
With increasingly urgent needs of a common technology platform and professional services from start-ups, the development of incubator becomes an indisputable trend. With core of national development strategies established as "enhancing independent innovation capability and building an innovative nation", professional technology business incubator has become a new topic in incubator development. This paper describes on the conception and feature of professional incubator, analyzes the technical incubators evolutionary path, and classifies the operation mode into four categories according to the investment and profit-making.
\end{abstract}

Keywords- Incubator; Professional Technology Business Incubator; Operation Model

\section{INTRODUCTION OF BUSINESS INCUBATOR}

Incubator, originally refers to the special equipment artificial hatching eggs, now means a space built for start-up companies to provide convenience in capital and management after introduced into economy field. It "hatches" the high-tech, scientific and technology enterprises to promote communication and development. In essence, it is a working space metaphor referring to economic organization "for selected companies to adding value by providing standard facilities and services with affordable expense".[2]

The research on business incubator can be divided into 3 aspects: macro, meso and micro:

Macro level refers to the relationship between incubator and macro-environment. Specifically speaking, it is the impact of macro-environment on the development of incubator, supporting system, government policy orientation and the relationship between the Sci-Tech Park and universities, etc.

Meso level refers to the mechanism of incubator system, objecting at the "field" of incubator, studying the network, industrialization, resource sharing with incubator as agent and the enterprise cluster.

Mirco level refers to the Internal operation and management of incubator system, including organizational structure, operating mechanism, business model and performance evaluation of business incubator, etc..

Studies on incubator in China focuses on 4 core problems:
The position of incubator. Chinese incubator origins from the national Sci-Tech Park, and serves for triple helix of the government, universities and industry, which an innovation in the business model between the government and the market. It in essence acts as a platform.

The operation mode of incubator. In the early stage, the incubator is divided into profit-making and public welfare ones. Incubator does not have conditions for profit at beginning, so services may be commercialized when conditions are not ripe.

The organizational management of incubator. The basic purpose of incubator is to organize public resources to help the companies add value and cultivate their core competitiveness with its distinctive capability.

The evaluation of incubator. This kind of research mainly focuses on the performance evaluation with different modern scientific management means, such as fuzzy mathematics, cluster analysis, hierarchy analysis, artificial neural network method and balanced scorecard. Future research may attach more importance on scientific methods, platform mechanism and system design.

\section{PROFESSIONAL TECHNOLOGY BUSINESS INCUBATOR AND ITS EVOLUTION}

\section{A. Introduction of Professional Technology Business Incubator}

Professional technology business incubator provides additional services on technology-sharing platform and professional technical support besides the common services. In the late 1990s, a new of business incubator came out. It is in a certain extent an enterprise-hatching attempt for the group's own development with the Group itself as investment background and a close connection between incubation and Investment Group's strategic goals.

However, problems have occurred in the operation of Chinese national incubators, such as short of funds, lack of talent, and the weakness of governmental support. Therefore, efforts should be made on the construction of public technical service platform, the set up of professional incubators, strengthening of investment, personnel training and 
innovation mechanism, [4] so as to be in trend with the diversified, marketized, specialized, networked and beneficial incubator industry development.[5]

\section{B. Feature of Professional Technology Business Incubator}

Compared with common business incubators, the professional incubator features in the following points:

- Professional incubator provides specific services to companies according to the specific needs, and thus helps to greatly reduce the initial cost, which is of highly importance to start-up enterprises. The specific services includes professional managements teams, technical support, help in new products development and market exploiting, commercialization of scientific and technological achievements, as well as providing of professional experimental base and technical platform.

- Professional incubator promotes the innovation ability in enterprises. Accumulated in the professional technology business incubator is a group of small and medium-sized enterprises from same or related industry based on specialization and cooperation, they gradually formed a an innovation community under the advantage of concentrated geographical location and information exchange. Under this professional environment, incubator creates a special relationship of competition and competence, which incentives in the incubator innovation.

- Professional incubator is conducive to the cultivation of virtual organization and learning organization. Professional technology business incubator is a talent and professional enterprise highland. Under the coordination of the incubator, a virtual organization with great flexibility can be combined to achieve the complementary advantages between enterprises. In professional technology business incubator, the close relationship between enterprises objectively creates learning atmosphere with communication of information and knowledge through formal and informal channels.

- Professional incubator provides a more professional service resources system. A good incubator is able to focus on core expertise and integrate internal resources as well as make full use of external service resources. Professional technology business incubator can maximally promote docking and integrate social resources and enterprise resources, effectively improve the professional level of intermediary service institutions, and ultimately forms a precise, detailed divisional labor service system cored in incubator.

- Professional incubator helps to form industrial clusters. With better project resources and formation of interactive state, professional incubator is conducive to the integration of incubators and venture capital. Each region has its unique resources and cultural and professional technology business incubator can give full play to the comparative advantages of the region by giving consideration to different regional industrial situation and the resource structure. The incubator helps to enhance the competitive advantage in region by giving full play to comparative advantages and attracting dominant powers of the aggregation, which leads to the formation of the specific industry cluster in the region.

In conclusion, the feature of professional technology business incubator are: professional management team, professional technical service facilities, professional consulting service team, specialized external business cooperation network, knowledge sharing management platform and a enterprise specialization cooperative relationship contributing to the formation of specialized gathering area.

\section{Evolution of Professional Technology Business Incubator}

Viewing from the development of professional technology business, the evolution can be divided in to 3 stages:

\section{1) Start-up Stage}

At this stage, the enterprise incubator is short in management skill, talent, technology, infrastructure, and so on. On one hand, business incubator attracts new ventures to hatch, and on the other hand, it establishes professional incubator service platform with recourses from universities and scientific research institutions. At this stage, the income of business incubator is relatively low, mainly from public services and facilities.

\section{2) Operation Stage}

There are two different operation modes in this stage: mode of non-profit organization and mode of company. Non-profit organizations generally refer to the non-governmental organizations in production, circulation and service filed with non-profit making purpose. Funded by the government, non-profit business incubator assumes part of the social welfare functions, and provides services to the incubatory enterprises with the advantage of transparent financial operations. While in some developed areas enjoying technology, talent, capital, and management advantages, incubator with self-development ability can choose the company operation mode. Studies show that "the ideal model for the cooperation of professional incubator and venture capital investment is to set up a capitalized professional incubator". (5) Therefore, company mode can be assumed as the choice for most business incubators. According to the requirements of company mode, the incubator should compose a limited liability company, attracts capitals, make clear limited liability and the property rights structure, elects the decision-making body: board of directors and supervisors, constructs corresponding incentive and restraint mechanisms, and operates company in accordance with the market.

3) Ecosystem Formation Stage

At this stage, some incubators may become truly independent and standardized non-profit organization, some 
may even become listed companies based on network membership and better governance structure, and some can become a real virtual enterprise (Net). Relationship between business incubators will change from competition to cooperation, leading to the formation of a cross-regional, cross-industry or even multinational incubator network. These incubators are no longer merely service providers relying on own resources; instead, they form an ecosystem with enterprises, partners and stakeholders. In this system, the organizer incubator, the main body of technological innovation entrepreneurial enterprises, and the strong support party: scientific research institutions, government and intermediary institution, together form an interdependent innovation ecosystem by technique flow, personnel flow, logistics and capital flow.

\section{THE OPERATION MODE OF PROFESSIONAL TECHNOLOGY BUSINESS INCUBATOR}

\section{A. Structure of Professional Technology Business Incubator}

Model refers to the general abstraction of the study objects. It focuses on the basic composition and mechanism of action, and reveals its value. Operation mode is the operation way and rule of the system.

The operation mode of professional technology business incubator is the generalization of the operation way and rule, including theoretical analysis and experience summary. It should be specific and characteristic in accordance with different countries, regions, environment and conditions.

The operation of professional technology business incubator concerns more than itself, it has close links with start-up, incubating and graduated enterprises, as well as external recourses.

For start-up enterprises, they need do be underdone a series inter-analysis before entering a professional technology business incubator; and for the incubating enterprises, both internal and external recourses are necessary for incubatory, which calls for the cooperation between external companies; and when comes to a stage, a professional technology business incubator will evaluate the hatching companies, to decide whether they will graduate or be eliminated.

\section{B. The Operation Mode of Professional Technology Business Incubator}

Foreign professional technology business incubator operation mode can be divided into non-profit and company mode. Similar to it, our national operation mode is usually classified into government-affiliated, institution enterprized and enterprized. If viewing from resource ownership and development strategy, it can also be divided into closed mode and open mode. Considering all the above factors and viewing from both investment entity nature and profit-making mode, this essay classifies operation mode into the following 4 kinds:

\section{1) Government-affiliated Mode}

Under the policy of Torch Program, the introduction, establishment and development of business incubator enjoys high importance. Therefore, at very beginning, almost all the incubators were invested by government and built in the Sci-Tech Park, and adopt government-affiliated mode.

In economic transformation period, this mode has irreplaceable advantages for new start-up technology SMEs in establish, develop and growth stage. With managers from government background, it is easy for incubators to communicate and coordinate with government, and making full use of all kinds of government resources. Besides, as a state-owned institution, it can help SMEs to get the support of capital, technology, market, collaboration and even personnel, enhancing competitive positions by being a protection umbrella. However, with the development of marketing economy, the drawbacks of this mode gradually exposed:

- The subject of investment is single. A serious shortage of investment may have negative effect on incubator development and functioning.

- Most of the staff with government background are lack of entrepreneurial experience, and have problems in providing effective help to new ventures;

- $\quad$ An excessive administrative intervention from the government may increase the randomness and risk in incubator decision of;

- the organization of incubator is loose and complex, which cause problems in too much Department division, unclear responsibilities, overstaffing, inefficient operation and poor service quality.

- $\quad$ The non-profit nature of government behavior is not suitable to the development of incubator. Managing staff with government background do not care about the incubator profit-making mode, they do not have the urgency and the corresponding stress in value creating.

Besides, the governmental assuming responsibility for state-owned assets value tends to make managers excessively cautious in the use of incubator funds. They will not take their own political future to risks, but only invest funds to the guaranteed income of the enterprise or project. This behavior is by no means in accordance with the incubator's original intention and purpose of cultivating and supporting new small high-tech venture with high risk, high growth and high yield.

With these problems gradually exposed, government-affiliated mode gradually withdraw from the stage of history.

\section{2) Institution Enterprized Mode}

Since problems in government-affiliated mode gradually exposed, Chinese MOST make policies to change to mode of the Innovation Service Center (incubator) into institution enterprized mode. This is a interim mode in the transition period of Chinese economic system. Playing a certain positive role in promoting the development of professional technology business incubators in China as it is, it also arouses confusion in theory and practice. The weakness of this mode lies in ineffective incentive for managers, incapability in motivating staff's initiative and enthusiasm, decision-making inefficiency, unitary subject of investment, serious shortage of funds, poor use of social capital and difficulty in attracting outstanding 
professionals, which seriously affect on incubators' service quality. Moreover, under this mode, some incubators with profit-making ability face limited development; some are relying on the mode, waiting for service instead of searching for development opportunities.

Under this situation, a new mode need to be taken, and the direction is very clear, that is to transform incubator operation mode into non-profit or enterprized mode.

\section{3) Non-profitable Mode}

Most of incubator founded by the state and local governments are non-profit. Their purpose is to support economic development, promote technology application, creating job opportunities, and realize the transform of scientific and technological achievements to productivity by helping and supporting start-ups.

Non-profit incubator has relatively strong government investment and management background, and generally set in central and western regions where economy is relatively backward, and poor in management, technology, talent, capital. It should make full use of all kinds of social resources, and take the virtualization operating mode. Virtualization operation is to introduce virtual incubator system in the non-profit professional technology business incubator to gradually become a "virtual organization". Virtual organization, with key function operated, has an open organizational structure, and is able to make full use of limited resources to achieve the optimal allocation of resources and constantly enhance the competitive advantage.

By a long time, we are bound by planned economy, stressing "independence, self-reliance", preferring "complete and package", consciously or unconsciously pursuing "large and all" or "small and all" business model, doing everything on our own and becoming a "functional-complete" small community short in features, advantages and competitiveness. Therefore, the concept of virtual organizations has an important reference for non-profit professional and technical business incubators. Virtual organizations need a "core." This "core" comes from company's core competencies. For virtualization profit professional technology business incubator, this "core" should be itself rather than other organizations. But being this core, an incubator should have unique "core competencies".

The "core" of non-profit professional and technical business incubators should mainly reflect in the professional services and environment. If operated as a "virtual organization", incubator's available resources are very limited. Therefore, it needs to aid in the form of a "virtual organization", make full use of social resources, and form a cooperative competitive advantage through outsourcing or strategic alliances. This requires an enhance in concept of competition, strengthening cooperation with relevant members of the value chain, an increase in value chain systems and improvement in the overall advantages of the value chain system to achieve bilateral or multilateral "win-win" objective. Selecting appropriate partner is of great importance in adopting "virtual organization" mode. Non-profit incubators should communicate and coordinate with partners, carry out the supervision, assessment, analysis and evaluation to ensure the smooth running of enterprise business services.

\section{4) Enterprise Mode}

Enterprise mode is suitable for profit incubator. Compared with the formers, this mode has following characteristics: First, an enterprise is investor owned enterprises with joint venture nature. Second, investors, or shareholders, declare limited liability according to investment amount. Third, the company has a separate ownership and management property. Fourth, property rights are clear. Fifth, shares and rights are equal. After nearly a hundred years of development, enterprise mode has become the most typical form in modern enterprise system. To find a suitable enterprise operation mode, China's profit incubator need to learn from the experience of developed countries' corporate governance, as well as combine with the national situation in our country.

According to the principle of comparative advantage and economies of scale theory, Inc. technical business incubators should adopt market-oriented mode of operation. Startups have difficulty in opening up the market with lack of funds, management experience, social impact, and high corporate credit. Incubator is designed to make up these deficiencies to nurture and incubate new venture organization. Cooperation between incubators and start-ups is in line with the comparative advantage principle, not also allowing entrepreneurs focus on research, technology development, marketing and other entrepreneurial activities, but also enable incubators provide a variety of services to improve the survival rate of start-ups, promote social entrepreneurship, and share entrepreneurial achievements.

Basing on the theory of economies of scale, new enterprises, especially technology start-ups are generally of small scale, and have higher cost in per capita administrative, personnel, finance, logistics and other administrative.Therefore, if start-ups entrusted part or all these management to incubator, they can form a scale, reduce new venture management costs, improve new venture management and resource efficiency, which is favorable to both start-ups and incubators. Professional and technical business incubators must be market-oriented, make use of market mechanisms to allocate resources needed to start-ups to survive and develop in the market competition by providing diversified services to both the inside and the outside of the new venture.

It is an important reform direction for incubator, especially those in developed regions to become for-profit organization through diversified social investment. The implementation of corporate system and formation of professional and technical Corporation Business Incubator Co. is beneficial in clear property rights, the establishment of decision-making bodies, supervisory bodies, and incentive and restraint mechanisms. In full accordance with market-oriented, autonomous and self-financing way, company manufactured into professional and technical business incubator with enterprise operating mode. 


\section{CONCLUSION}

Professional technological business incubator is an advanced stage of incubator development, and has gone through start-up, operation and ecosystem stage in evolution. Companied with common incubators, it has professional management team, technical services, consulting services team, business cooperation network, expertise management sharing platform, and specialized cooperation in companies contributing to the formation of specialized gathering area. Viewing from both investment entity nature and profit-making mode, the operation mode can be classified into the government-affiliated, institution enterprized, non-profit and enterprise mode.

With the rapid development of economic globalization and information technology, the integration, cross-border, win-win and all connection features in "Internet + " will also be reflected in the professional technology incubator development. Therefore, professional technology incubators will usher in a new stage of its development with a trend embodies characteristics of network, platform, branding, international and diversification.

\section{ACKNOWLEDGEMENT}

This research was financially supported by the National Natural Science Foundation of China (Project number: 71372196G0203).

\section{REFERENCES}

[1]. Shao Jungang, Chang Linzhao, "The Operation and Management of Professional Technology Business Incubator", Economy and Technology Press, Beijing, 2008.

[2]. Wang Luhao, Wang Cheng, "The Concept of Incubator and Its Evolution---A Grounded Theory Analysis Based on "People's Daily" Database", Studies on Science of Science, pp. 493-500, Apr. 2014.

[3]. Wang Shuilian, "Research on Incubators: A Domestic Literature Review from 1989 to 2012", Journal of Gansu Lianhe University (Social Science), pp. 9-13, Jul. 2013.

[4]. Lin Dechang,Liao Beiqiu, Lu Qiang,Wang Weihong, "The Study on Influential Factors of Service Innovation of Business Incubator", Studies on Science of Science, pp. 920-925, Jun. 2010.

[5]. Liang Yunzhi, Si Chunlin, "Study on the Incubator Business Mode: Theory Structure and Empirical Analysis", R\&D Management, pp. 44-50, Feb. 2010.

[6]. Si Chunlin, Liang Yunzhi, "The Incubator Business Model and Its Development ---Case Analysis". Economy Management, pp.169-177, Oct., 2010. 